for the answers (if they exist) to the questions to come?

The answer depends on how much time you have available and how much you want to know about the background to the topic. If the answer to both is "a lot" then this volume is for you, but be warned, it does not make light reading.

The editors set out to "provide a critical assessment of the status of neural transplantation across the range of applications currently under consideration" (chapter 1, Introduction), limiting themselves (and the individual chapter authors) to central nervous system considerations. Understandably, a large proportion of the chapters deal with rodent models of neurodegenerative disease especially Parkinson's disease, and the effects of grafting in these systems. These reviews are comprehensive and well written and provide a fascinating insight into the observations which have led to the human application of neural transplantation. The editors are to be congratulated for arranging the contributions in a manner which leads one from these initial rodent experiments (chapters 2 and 3 ) through non-human primate paradigms (chapter 4) to transplantation in humans (chapter 5). This chapter, by Lindvall, reviews the history, methodology, and results of the human trials of transplantation. It would serve admirably as a source for finding one's feet if this were one's first journey into the field, although it does, at times, seem a little dismissive of adrenal medulla transplantation.

Chapter 7 (Bjorklund et al) discusses functional aspects of striatal transplants in the rat $\mathrm{HD}$ model and presents a convincing argument for taking tentative steps towards human experimentation. In addition to reviewing the data on the improvements in aspects of motor behaviour after transplantation we are told that grafted human fetal striatal neurones can extend axonal projections (for up to $2 \mathrm{~cm}$ ) and that host dopaminergic afferents are capable of modulating the neuronal activity of the transplant. The authors conclude this chapter, however, with a caution on the need for further studies in non-human primates to validate the applicability of the rodent observations.

Chapters 9 to 13 review the status of transplantation to reverse cognitive impairment, discussing rodent and non-human primate model systems. The chapters are again well written, comprehensive and impressively referenced. The editors have again ensured that each contribution follows logically from those preceding.

Chapters 14 to 19 cover areas currently less advanced in their clinical potential including transplantation in ischaemia, grafts in epilepsy, modulation and restitution of circadian rhythms, and recovery after spinal cord injury.

The final chapter is a discussion of the proposed mechanisms by which neural grafts may restore function. The editors conclude that there is no single or simple answer to the question: How do grafts work? They and the other contributors have, however, throughout this volume, provided us with a wonderful insight into the research which has shown that neural transplantation, in a variety of situations, does work and that it will have place in clinical practice.

Although I have no reservations in recommending this volume, I doubt whether would be purchased by a clinical geneticist without a particular interest in Huntington's disease. I think it equally unlikely that it will be found in most genetics departmenta libraries. It is a volume, however, which it is useful to know exists and which one can turn to for a comprehensive account of the current status of neural transplantation.

JOHN C MACMILLAN

Inherited Disorders of the Thyroid System. G Medeiros-Neto, J B Stanbury. (Pp 221; 131.50.) UK: Times Mirror International Publishers/CRC Press. 1994.

Over the last 40 years an increasing number of inherited disorders affecting the thyroid system have been identified. These range from specific inborn errors of metabolism primarily involving iodide transport to sub sequent organification to thyroglobulin expression and secretion. More recently specific receptor defects of the thyrotropin stimulatory hormone have been characterised. In addition, an inherited predisposition to thyroid disorders has been identified, particularly with regard to autoimmune thyroid disease.

It is therefore timely for a monograph to appear that has reviewed the genetic contribution to thyroid dyshormonogenesis and regulation.

Professor Stanbury has individually made an enormous contribution to this field. It is therefore appropriate that he should be associated with such a monograph which sets out in an ordered manner to cover the range of disorders that one may, albeit uncommonly, encounter within the practice of clinical genetics. Perhaps it is because of the infrequent exposure to such patients that the clinical geneticists would do well to have access to this monograph, at least as a ready source of additional references. However, on careful reading, the style of the monograph is somewhat uncomfortable in places and of course is specifically targeted to aspects of thyroid dysfunction. For example, in an otherwise excellent chapter reflecting the clinical variability in Pendred's syndrome (congenital deafness and sporadic goitre), the clinica studies are solely confined to aspects of thyroid pathology with little detail of the audiological findings that characterise this disorder Descriptions of molecular genetic studies lack clarity and are unlikely to help the more general reader.

Overall the book is up to date and has been referenced from a wide source. Each of the
12 chapters carries a useful single page summary for rapid assessment of key points. I would consider this monograph to be a useful addition to the general medical library.

RICHARD TREMBATH

NOTICES

\section{Inherited disorders and their genes in different European populations}

This conference will be held in St Feliu de Guixols, Spain, on 11-15 November 1995. (Conference organiser: Peter Harper. Coorganisers: Jaume Bertranpetit, Albert de la Chapelle, Angus Clarke.) Applications are invited to participate in this meeting, the second in a series of European Research Conferences on the topic. The aim of the conference is to allow Clinical, Molecular, and Population Geneticists to share data and hypotheses, both with each other and with scientists from other disciplines, such as archaeology and anthropology. The number of participants will be limited to around 100 people. Younger research workers with relevant data to present and discuss will be especially welcome; specific financial support may be available for these and also for participants from Eastern Europe. In view of the wide interest in the subject and the success of the previous meeting in Strasbourg, it is likely that there will be considerably more applicants than can be accepted. Thus early application to the ESF Conference Office is advised; the latest date for applications is 1 July 1995. Applications to Caroline Grimont, Conference Manager, European Science Foundation, European Research Conferences, 1 Quai Lezay Marnésia, F-67080 Strasbourg Cedex, France. Fax: 33883669 87.

\section{5th International Congress on Trace Elements in Medicine and Biology}

Therapeutic Uses of Trace Elements Satellite Workshop: Molecular Basis of Copper Metabolic Disorders. This congress will be held in Méribel, France, on 4-7 February 1996. Further information from Madame Arlette Alcaraz, Laboratoire de Biochimie CCHRUG - BP 217, F-38043 Grenoble Cedex 9, France. Tel: (33) 767654 84. Fax: (33) 76765664 